\title{
El mercado mundial del litio y el eje asiático. Dinámicas comerciales, industriales y tecnológicas (2001-2017)
}

\author{
Julián Zícari \\ UBA-CONICET, Buenos Aires, Argentina. \\ Email: sanlofas@hotmail.com \\ Bruno Fornillo \\ UBA-CONICET, Buenos Aires, Argentina. \\ Email: bfornillo@filo.uba.ar \\ Martina Gamba \\ UNLP-CONICET, La Plata, Argentina. \\ Email: martina.gamba@cetmic.unlp.edu.ar
}

\begin{abstract}
Resumen: La dinámica de intercambio global del litio, el control de su cadena de valor y el mercado de las baterías de Ion-Litio son un indicador de primer orden acerca de las relaciones norte-sur y de las estrategias de desarrollo contemporáneas que aplican los países, ya que el litio se encuentra en el corazón de un nuevo paradigma energético. Sobre la base de datos estadísticos, nuestro objetivo es analizar las dinámicas comerciales de la materia prima litio, de las pilas, baterías y acumuladores, además de dar cuenta de los patrones globales de innovación y de los mercados de consumo de productos finales como los automóviles. Por resultado describimos un corrimiento pronunciado del eje dominante de control de la tecnología del litio hacia el sudeste asiático, el cual deja atrás a las economías atlánticas a la vez que se reedita un patrón dependiente en las relaciones norte-sur.
\end{abstract}

Palabras claves: China, litio, baterías, relaciones norte-sur, geopolítica

\section{The world lithium market and the Asian axis. Commercial, industrial and technological dynamics (2001-2017)}

\footnotetext{
Abstract: The dynamics of global lithium exchange, the control over its value chain and the market for lithium-ion batteries are a prime indicator of the north-south relations and contemporary development strategies applied by countries, since lithium is at the heart of a new energy paradigm. Based on statistical data, our objective is to analyze the commercial dynamics of lithium raw material, of batteries and accumulators, as well as to account for global innovation patterns and consumer markets of final products such as automobiles. As a result, we describe a pronounced shift in the dominant axis of lithium technology control toward Southeast Asia, which leaves the Atlantic economies behind while reissuing a dependent pattern in north-south relations.
}

Keywords: China, lithium, batteries, north-south relations, geopolitics 


\section{O mercado mundial de lítio e o eixo asiático. Dinâmicas comerciais, industriais e tecnológicas (2001-2017)}

Resumo: A dinâmica de intercâmbio global do lítio, o controle de sua cadeia de valor e o mercado de baterias de Íon-lítio são um dos principais indicadores das relações Norte-Sul e das estratégias de desenvolvimento contemporâneas aplicadas pelos países, já que o lítio está no coração de um novo paradigma energético. Com base em dados estatísticos, nosso objetivo é analisar as dinâmicas comerciais da matéria-prima de lítio, das baterias e acumuladores, bem como explicar os padrões globais de inovação e os mercados consumidores de produtos finais, como os automóveis. Como resultado, descrevemos uma mudança acentuada no eixo dominante de controle da tecnologia do lítio para o Sudeste Asiático, que deixa para trás as economias do Atlântico enquanto reeditam um padrão dependente nas relações norte-sul.

Palavras-chave: China, lítio, baterias, relações norte-sul, geopolítica

$* * *$

El 68\% de las principales reservas del litio se encuentran en los andes sudamericanos. La dinámica, desde su extracción hasta su constitución en células de energía, es un vector privilegiado para ofrecer un panorama sobre las relaciones norte-sur y sobre el curso de la geoeconomía global, pues sin esa mirada de gran escala es imposible comprender qué sucede con este elemento químico. En la actualidad, los países dominantes encaran diferentes estrategias para hacerse de tecnología de punta, captar rentas de innovación y asegurar sus propios entramados productivos de base. El litio impacta de lleno en estas estrategias porque está en el corazón de la economía venidera, esto es, una renovada industria energética. La densidad de esta tecnología del litio en cada uno de los países y su potencial vinculación con patrones ambientales sólidos, permiten calibrar los rumbos posibles de las nuevas políticas de desarrollo o, mejor dicho, de posdesarrollo.

Las peculiares propiedades físicas y químicas del metal lo hacen atractivo para muchísimas aplicaciones: en formulaciones de grasas lubricantes, en la preparación de aleaciones muy livianas y resistentes, en aditivos a cementos y cerámicos, en sistemas de refrigeración y de purificación de aire en espacios cerrados, en fármacos ampliamente difundidos y de utilización a nivel mundial, en tecnología nuclear, entre otras. Sin embargo, el advenimiento de las baterías de litio como el dispositivo de almacenamiento de energía más eficiente de las últimas décadas y vital en la sociedad pos fósil hace de esta aplicación la más prometedora.

En este artículo, caracterizamos el conjunto del entramado mercantil, productivo y tecnológico que conlleva el litio desde su extracción primera hasta su conversión en un producto final, prestando especial atención al intercambio internacional de bienes. Damos cuenta de las dinámicas comerciales -tanto en la importación y exportación del litio como de las células de energía- junto con patrones de producción de baterías, investigación de su tecnología y consumo de sus productos, con el objetivo de brindar una mirada amplia sobre la geopolítica global del litio. En efecto, abordar la dinámica del mercado mundial del litio nos ofrece dos ricas oportunidades. Por un lado, nos permite aproximarnos al funcionamiento de uno de los mercados más interesantes para un recurso natural en términos de su comercialización, y también de las prometedoras características que posee su procesamiento en términos industriales y tecnológicos. Por otro, introducirnos en este mercado también nos ofrece una foto bastante aproximada acerca de los diferentes movimientos del mercado mundial a nivel general y de la dinámica actual del capitalismo, con regiones, productos y tendencias que indican la consolidación de nuevos esquemas geopolíticos y bloques económicos en las primeras décadas del siglo XXI, donde el eje asiático se está volviendo fundamental. Porque, al introducirnos en el ciclo económico, productivo, comercial y tecnológico del litio, se podrán vislumbrar varios de los rasgos actuales de los mercados mundiales de intercambio y su estructura, donde las potencias económicas centrales del siglo XX (Estados Unidos, Alemania, Japón, Francia) se ven cada vez más rezagadas y eclipsadas frente al fuerte dinamismo surasiático, especialmente el generado por China.

De este modo, una de las principales hipótesis de este trabajo es que la imagen de un dominio homogéneo de los países centrales en el campo de la producción e innovación de alta tecnología debe ser matizada e incluso abandonada a la luz de lo que acontece con el litio, puesto que a través de él puede verse la rapidez con la que la "casa común asiática” ha tomado la delantera en el conjunto de la economía del litio, desde los inicios 
de la cadena hasta el consumo propio de sus productos claves, como los automóviles. En este marco, el litio parece ser un ejemplo más del empuje que, luego de la crisis del año 2008, el gobierno chino realizó para situarse a la vanguardia de la nueva tecnología verde.

El escrito se divide en cuatro secciones. En la primera se describe la dinámica del mercado mundial del litio en tanto recurso primario, dando cuenta de quiénes son sus poseedores, los precios, quiénes lo exportan y quiénes lo demandan. En la segunda sección se abordan los patrones de la producción industrial ligada a la tecnología del litio. En una tercera sección se presentan los últimos desarrollos en investigación e innovación referidos a la tecnología del litio. La cuarta sección refiere a la industria automotriz puesto que es uno de los mercados más prometedores e importantes de la economía vinculada al litio. Finalmente, el trabajo cierra con algunas conclusiones al respecto.

\section{La dinámica mundial del litio como recurso primario (2001-2017)}

Para comenzar nuestro recorrido es necesario analizar brevemente qué países poseen el recurso del litio y de qué formas. Al revisar los movimientos de los mercados y los tipos de comercialización que realizan los países, debemos destacar que el litio no es un producto "homogéneo" sino que se comercializa a través de distintas formas ${ }^{1}$. En este trabajo abordaremos las tres principales formas de comercialización del litio como derivado, que refieren a modos diversos de elaborar mínimamente el recurso primario. De este modo, prácticamente no tendremos en cuenta lo sucedido con la exportación australiana, que se da centralmente en torno a concentraciones en pegmatitas y sin tener casi elaboración del recurso, y que por ello suele ocupar el primer puesto como comercializador mundial según la medición en $\mathrm{LCE}^{2}$. Ya que la materia prima del litio se comercializa de forma segmentada y de manera diferencial según su tipo, sólo se analizarán las formas de exportaciones centrales de los países del "triángulo del litio" sudamericano, las cuales se realizan como "carbonato de litio" (la forma que explica casi las dos terceras partes del mercado mundial considerado en este escrito) y como óxido e hidróxido de litio (formas que explican el tercio restante).

Si consideramos los datos que nos muestra el Gráfico 1, notaremos que un $58 \%$ del total de litio se halla en los salares de salmuera -hoy en día la forma más rentable de explotación del recurso en términos económicos-, seguido por las pegmatitas y el granito (26\%), las arcillas (7\%) y otras formas menores (existe una levísima concentración de litio en el mar que no resulta significativa).

\section{Gráfico 1}

\section{Distribución de las reservas mundiales del litio por fuente}

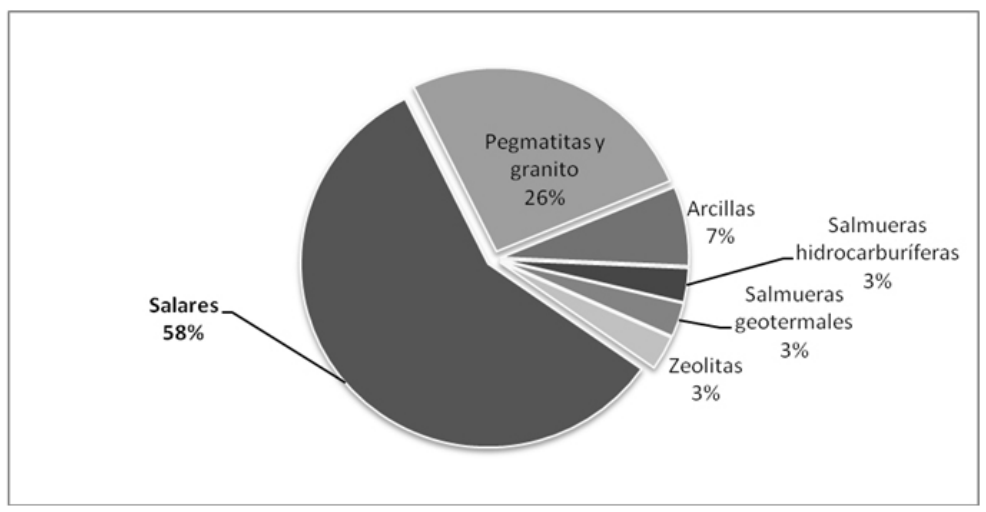

Fuente: Elaboración propia en base a datos de Ministerio de Energía y Minería de Argentina (2017) 
A su vez, a la luz del Gráfico 2, en la distribución de los recursos según los países, se observa la fuerte concentración de los Andes Sudamericanos, donde el denominado “Triángulo del litio” compuesto por Bolivia (30\% de las tenencias totales de litio), Chile (21\%) y Argentina (17\%) da cuenta del 68\% de las reservas mundiales del recurso, seguido en un lejano y cuarto lugar por Australia (7\%) y otros países ${ }^{3}$.

\section{Gráfico 2}

Distribución geográfica de los recursos mundiales del litio por país

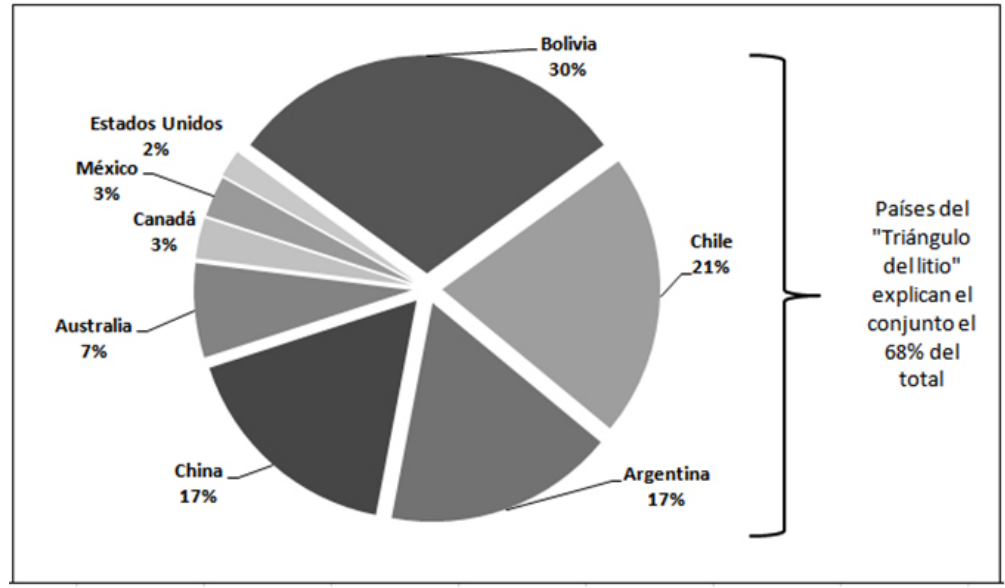

Fuente: Elaboración propia en base datos de Ministerio de Energía y Minería de Argentina (2017).

Si seguimos los datos resumidos en el Gráfico 3 y provistos por Comtrade -organismo que extrae su información de Naciones Unidas-, notaremos varios elementos a considerar. En líneas generales es fácil ver que entre 2001 y 2017 los valores comercializados del litio en las formas destacadas aquí se multiplicaron 14 veces, aunque no de manera sostenida sino con tres subperíodos muy claros y distintos entre sí. Desde 2001 hasta 2008, el mercado se multiplicó por cuatro, creciendo a un ritmo del 30\% anual. Sin embargo, con la irrupción de la crisis financiera mundial sobre la segunda mitad de 2008 y principios de 2009 el mercado se deprimió y luego estancó por cinco años hasta 2013, momento en que los valores previos no sólo se fueron recuperando sino que incluso tuvieron un crecimiento espectacular desde 2015: desde este último año la comercialización prácticamente se triplicó para el tramo 2015-2017 al crecer al 45\% anual.

\section{Gráfico 3}

\section{Comercialización de carbonato, óxido e hidróxido de litio y totales a nivel mundial} (en miles de dólares) (2001-2017) ${ }^{4}$

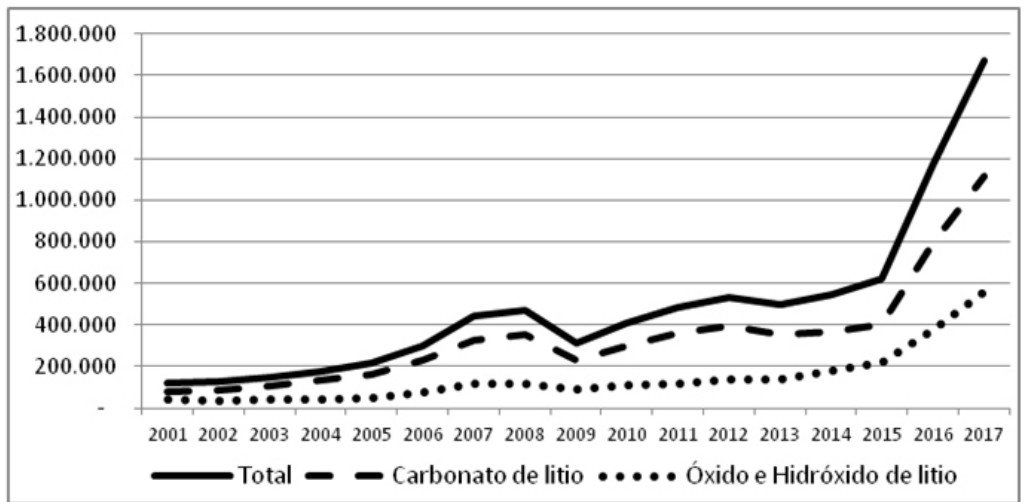

Fuente: Elaboración propia en base a datos de Comtrade 
Las tendencias arriba señaladas, que acompañan bastante bien tanto las dinámicas de la economía mundial durante el plazo considerado como los subperíodos marcados, se expresan también en la evolución de los precios de los productos descritos y que hemos plasmado en el Gráfico 4, de modo que construimos un valor de referencia pese a que el litio no se comercializa en mercados abiertos. En líneas generales, el aumento sostenido de la comercialización del litio es un indicador de la consolidación de las baterías de litio como tecnología de acumulación electrónica privilegiada en el mercado mundial.

\section{Gráfico 4}

Precios mundiales del carbonato, óxido e hidróxido de litio(en miles de dólares por tonelada) $(2001-2017)^{5}$

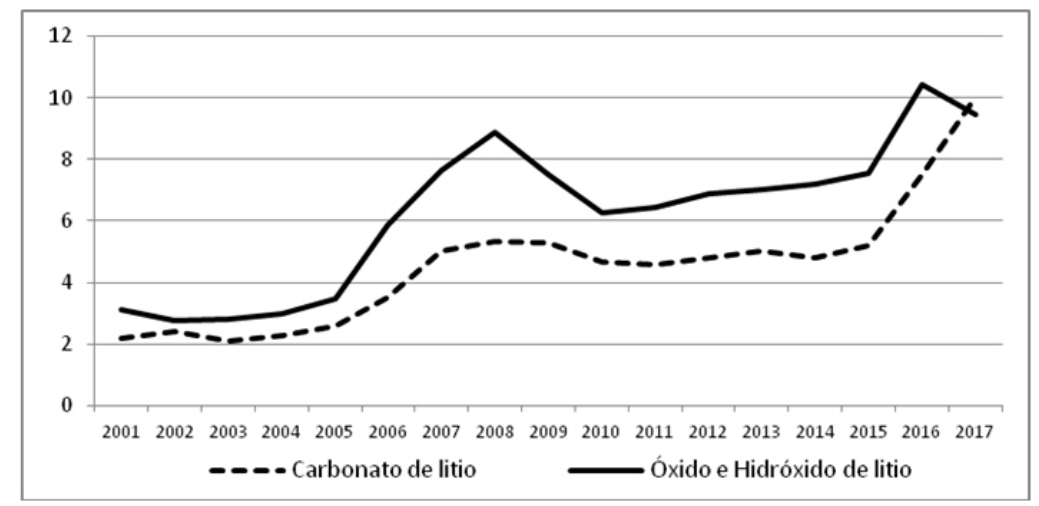

Fuente: Elaboración propia en base a datos de Comtrade

$\mathrm{Al}$ analizar la exportación encontramos otras diferencias. Siguiendo los datos resumidos en el Cuadro 1 vemos que la venta de carbonato de litio estuvo totalmente hegemonizada por la actuación de Chile, país que explicó entre 2001 y 2017 entre el 50\% y el 65\% de lo exportado según el año. A su vez, también se sigue que los cambios más notorios de este tipo de producto fueron tres: el primero se refiere al crecimiento de Argentina como exportador mundial, ya que dicho país pasó de tener una participación de apenas el 1,18\% del mercado en 2002 a cubrir el 19,54\% en 2016 (es decir, su capacidad como país exportador creció a una velocidad todavía más alta que la del mercado en general, convirtiéndose en el segundo exportador mundial aunque todavía lejos de Chile). El segundo dato a considerar es la pérdida de participación relativa de Estados Unidos, país que pasó de explicar casi el 13\% en 2001 a representar menos del 2\% en 2017, con lo que quedó muy rezagado en términos de su peso como vendedor. Por último, si bien marginal por ahora ya que se encuentra en su fase piloto, desde 2016 se observan las primeras exportaciones de Bolivia, lo cual podría volverse un dato a considerar hacia el futuro ya que este país cuenta con el yacimiento de litio de salmueras más grande del mundo (el salar de Uyuni), por lo que no sería ilógico que en los próximos años Bolivia creciera a una buena velocidad en su participación (en los hechos, proyecta exportar 15.000 toneladas anuales de litio).

Por el lado de la producción de óxido e hidróxido de litio el panorama es otro. Aquí se notó una fuerte mutación en términos de participación exportadora: si al comenzar el siglo Estados Unidos explicaba más de la mitad del mercado mundial, en el año 2017 este país pasó a ocupar el segundo lugar al ser relegado por China, que se convirtió en el primer exportador en términos internacionales exportando el 35\% del total en 2017, cuando en 2001 sólo cubría el 15\%. Un fenómeno similar al chino fue el de Chile, que si bien todavía está lejos de dominar cómodamente lo exportado de óxido e hidróxido de litio, creció en similar proporción: a comienzos de siglo no exportaba nada y en la actualidad es el tercer exportador mundial, con el 18\% del mercado, con una dinámica lo suficientemente poderosa como para estar muy cerca de superar a Estados Unidos. Donde en líneas generales se nota un mercado de exportaciones de óxido e hidróxido de litio mucho menos concentrado que en el caso del carbonato, en este último caso Chile y Argentina -solo dos países- explican el $80 \%$ del total. Asimismo, vale la pena considerar que en ambos mercados del litio, Bélgica ha logrado mantener una participa- 
ción nada despreciable y cercana al 7\% del total (lo cual nos habla de los fenómenos de reexportación, dado que el país europeo no produce litio ${ }^{6}$. Por último, vale mencionar que gran parte de la exportación del litio en cualquiera de sus formas se encuentra en manos de cuatro corporaciones globales: SQM, Rockwood/Albemarle, FMC y Talison (Ströbele-Gregor, 2015), aunque el auge de la demanda del litio lleve a que en la actualidad se pluralicen los actores empresariales que buscan participar del mercado.

\section{Cuadro 1}

Participación de los países exportadores de carbonato, óxido e hidróxido de litio, en porcentaje (2001-2017)

\begin{tabular}{|c|c|c|c|c|c|c|c|c|c|c|c|c|c|c|c|c|c|}
\hline & 2001 & 2002 & 2003 & 2004 & 2005 & 2006 & 2007 & 2008 & 2009 & 2010 & 2011 & 2012 & 2013 & 2014 & 2015 & 2016 & 2017 \\
\hline \multicolumn{18}{|c|}{ Carbonato de litio } \\
\hline Chile & 60,91 & 62,38 & 59,87 & 56,41 & 57,20 & 54,51 & 58,81 & 61,12 & 51,59 & 58,52 & 59,43 & 65,90 & 63,36 & 60,58 & 61,17 & 59,55 & 61,40 \\
\hline Argentina & 2,90 & 1,18 & 5,58 & 9,79 & 10,07 & 11,56 & 9,25 & 13,93 & 18,40 & 15,95 & 11,32 & 11,34 & 11,44 & 13,92 & 15,99 & 19,54 & 17,78 \\
\hline Bélgica & 7,11 & 8,33 & 7,23 & 7,40 & 7,85 & 8,58 & 9,25 & 5,68 & 7,81 & 7,17 & 5,83 & 6,53 & 10,01 & 7,69 & 9,05 & 8,85 & 7,59 \\
\hline China & 3,34 & 2,93 & 2,56 & 2,44 & 3,46 & 7,57 & 6,52 & 4,52 & 6,30 & 6,64 & 10,03 & 5,50 & 2,61 & 3,95 & 3,23 & 3,68 & 2,41 \\
\hline Alemania & 6,49 & 5,96 & 7,33 & 6,51 & 6,51 & 6,35 & 5,90 & 5,08 & 6,59 & 5,01 & 6,26 & 4,62 & 6,29 & 6,62 & 4,95 & 2,85 & 3,04 \\
\hline EEUU & 12,93 & 14,44 & 11,92 & 11,40 & 10,50 & 6,59 & 5,57 & 6,40 & 4,92 & 4,06 & 3,72 & 3,53 & 3,37 & 2,86 & 2,65 & 1,76 & 2,08 \\
\hline Bolivia & 0,00 & 0,00 & 0,00 & 0,00 & 0,00 & 0,00 & 0,00 & 0,00 & 0,00 & 0,00 & 0,00 & 0,00 & 0,00 & 0,00 & 0,00 & 0,02 & 0,04 \\
\hline Otros & 6,32 & 4,79 & 5,51 & 6,05 & 4,41 & 4,84 & 4,70 & 3,26 & 4,40 & 2,66 & 3,41 & 2,58 & 2,92 & 4,39 & 2,96 & 3,73 & 5,66 \\
\hline Total (en ) & 100,00 & 100,00 & 100,00 & 100,00 & 100,00 & 100,00 & 100,0 & 100,00 & 100,00 & 100,00 & 100,00 & 100,00 & 100,00 & 100,00 & 100,00 & 100,00 & 100,00 \\
\hline \multicolumn{18}{|c|}{ Oxido e hidróxido de litio } \\
\hline China & 15,04 & 15,45 & 17,78 & 12,70 & 16,92 & 12,02 & 22,35 & 14,30 & 12,77 & 12,29 & 21,95 & 17,00 & 22,88 & 25,30 & 33,62 & 37,80 & 35,35 \\
\hline EEUU & 54,97 & 56,87 & 51,76 & 48,71 & 43,45 & 40,06 & 34,84 & 35,27 & 36,43 & 37,07 & 35,29 & 37,24 & 35,37 & 35,27 & 37,62 & 19,72 & 20,67 \\
\hline Chile & 0,00 & 0,00 & 0,00 & 0,13 & 1,42 & 24,75 & 23,42 & 26,39 & 21,87 & 21,53 & 21,49 & 20,27 & 15,45 & 15,74 & 12,65 & 16,56 & 18,18 \\
\hline Rusia & 9,20 & 8,39 & 9,68 & 12,75 & 16,40 & 2,00 & 1,35 & 0,54 & 1,67 & 1,07 & 4,75 & 9,28 & 5,46 & 8,32 & 5,70 & 11,88 & 11,53 \\
\hline Bélgica & 3,17 & 4,59 & 6,72 & 12,79 & 13,79 & 10,11 & 8,87 & 8,33 & 6,35 & 10,98 & 9,25 & 11,05 & 12,91 & 9,80 & 6,79 & 8,51 & 7,85 \\
\hline Otros & 17,63 & 14,70 & 14,06 & 12,92 & 8,01 & 11,06 & 9,17 & 15,17 & 20,90 & 17,05 & 7,27 & 5,16 & 7,93 & 5,58 & 3,62 & 5,52 & 6,42 \\
\hline Total (en ) & 100,00 & 100,00 & 100,00 & 100,00 & 100,00 & 100,00 & 100,0 & 100,00 & 100,00 & 100,00 & 100,00 & 100,00 & 100,00 & 100,00 & 100,00 & 100,00 & 100,00 \\
\hline
\end{tabular}

Fuente: Elaboración propia en base a datos de Comtrade

Al analizar el consumo del litio y en función de los datos presentados en el Cuadro 2, notamos un fenómeno que ya hemos destacado en investigaciones previas (Zícari, 2015a), en el cual los países demandantes del recurso son indefectiblemente las naciones del norte global. Es decir, si en términos de exportaciones existen países tanto del centro como de la periferia, la importación masiva es en cambio unidireccional: solo las naciones más ricas y avanzadas son las que lo consumen, sin existir países periféricos que lo demanden en gran escala. Para el caso de las importaciones de carbonato de litio se evidencian las mutaciones típicas que presentó la economía mundial durante estos años, si Estados Unidos ocupaba el primer lugar de la serie al comenzar el siglo XXI seguido por Japón y luego por Alemania, luego asistimos a una notoria mutación: China y Corea pasaron a tomar la delantera de lo importado (siendo entonces los grandes responsables del crecimiento de lo demandado a nivel mundial) para dejar en lugares cada vez menos significativos y decrecientes tanto a Estados Unidos como a Alemania.

En el caso del óxido e hidróxido de litio, las transformaciones en la demanda han sido menores en términos del ranking de consumo y se presentó un proceso de concentración en manos de Japón y luego de Corea, que pasaron de explicar entre ambos el 20\% de lo consumido en 2001 a casi el 60\% en 2017. En todos los casos, para el carbonato, el óxido y el hidróxido de litio, es claro que en la actualidad los principales países del sudeste asiático (China, Corea y Japón) explican por sí mismos dos tercios de lo demandado por el mercado, los principales países europeos cerca del 10\% (Alemania, Gran Bretaña, Bélgica y Francia) y Estados Unidos un promedio del $6 \%$, siendo una muestra de las transformaciones que ha estado asumiendo la economía mundial. Estas tendencias adquieren una mayor significación si es posible explicar el destino del consumo y las reconfiguraciones en la producción tecnológica e industrial, operadas a nivel internacional. Avancemos hacía allí entonces. 


\section{Cuadro 2}

Participación de los países importadores de carbonato, óxido e hidróxido de litio, en porcentaje (2001-2017)

\begin{tabular}{|c|c|c|c|c|c|c|c|c|c|c|c|c|c|c|c|c|c|}
\hline & 2001 & 2002 & 2003 & 2004 & 2005 & 2006 & 2007 & 2008 & 2009 & 2010 & 2011 & 2012 & 2013 & 2014 & 2015 & 2016 & 2017 \\
\hline \multicolumn{18}{|c|}{ Carbonato de litio } \\
\hline China & 11,38 & \begin{tabular}{|l|}
9,78 \\
\end{tabular} & 11,06 & 12,38 & 13,70 & 10,31 & 6,71 & 6,58 & 5,30 & 9,51 & 8,77 & 14,83 & 19,40 & 18,03 & 14,07 & 23,70 & 26,13 \\
\hline Corea & 3,69 & 2,96 & 3,57 & 3,87 & 4,18 & 4,28 & 6,81 & 9,07 & 13,46 & 13,69 & 13,82 & 16,13 & 19,57 & 20,96 & 21,97 & 20,28 & 22,10 \\
\hline Japón & 18,73 & \begin{tabular}{|l|}
19,17 \\
\end{tabular} & 21,80 & 21,04 & 16,90 & 27,15 & 26,10 & 24,70 & 21,82 & 25,98 & 21,11 & 16,53 & 12,55 & 17,12 & 16,02 & 16,36 & 17,43 \\
\hline Bélgica & 8,10 & 8,28 & 6,09 & 7,17 & 8,16 & 8,04 & 8,76 & 7,04 & 7,90 & 6,05 & 8,66 & 7,43 & 9,38 & 5,92 & 10,06 & \begin{tabular}{|l|}
10,05 \\
\end{tabular} & 8,14 \\
\hline EEUU & 19,95 & 19,22 & 18,55 & 21,42 & 18,68 & 17,37 & 17,37 & 20,63 & 18,39 & 14,40 & 15,26 & 13,73 & 13,59 & 12,34 & 15,07 & 9,92 & 7,20 \\
\hline Rusia & 4,60 & 4,16 & 2,87 & 3,61 & 3,78 & 1,21 & 1,20 & 1,23 & 0,84 & 0,98 & 2,27 & 1,91 & 1,80 & 2,77 & 1,98 & 4,33 & 4,25 \\
\hline Alemania & 10,17 & 11,28 & 11,70 & 10,82 & 11,02 & 10,21 & 10,04 & 9,16 & 9,43 & 9,85 & 10,92 & 11,81 & 2,94 & 2,93 & 3,97 & 2,45 & 3,93 \\
\hline Otros & 27,98 & 29,30 & 27,23 & 23,31 & 27,34 & 22,64 & 24,20 & 22,83 & 23,70 & 20,52 & 21,47 & 19,54 & 22,57 & 22,71 & 18,84 & 17,25 & 15,06 \\
\hline Total & $\begin{array}{l}100,0 \\
0\end{array}$ & $\begin{array}{l}100,0 \\
0\end{array}$ & $\begin{array}{l}100,0 \\
0\end{array}$ & $\begin{array}{l}100,0 \\
0\end{array}$ & $\begin{array}{l}100,0 \\
0\end{array}$ & $\begin{array}{l}100,0 \\
0\end{array}$ & 100,0 & $\begin{array}{l}100,0 \\
0\end{array}$ & $\begin{array}{l}100,0 \\
0\end{array}$ & 100,00 & $\begin{array}{l}100,0 \\
0\end{array}$ & 100,0 & $\begin{array}{l}100,0 \\
0\end{array}$ & $\begin{array}{l}100,0 \\
0\end{array}$ & 100,00 & $\begin{array}{l}100,0 \\
0\end{array}$ & 100,00 \\
\hline \multicolumn{18}{|c|}{ Oxido e hidróxido de litio } \\
\hline Japón & 16,23 & 12,32 & 16,25 & 13,49 & 11,43 & 15,98 & 17,31 & 15,88 & 19,26 & 22,59 & 22,61 & 26,51 & 14,55 & 29,98 & 34,40 & 23,86 & 38,83 \\
\hline Corea & 4,73 & 4,80 & 4,04 & 6,72 & 4,76 & 3,52 & 3,72 & 4,01 & 5,10 & 5,81 & 7,17 & 7,74 & 8,13 & 10,22 & 13,13 & 24,08 & 23,51 \\
\hline India & 5,81 & 6,74 & 7,52 & 6,82 & 13,45 & 9,83 & 11,08 & 9,74 & 10,77 & 10,50 & 9,38 & 7,48 & 12,59 & 6,76 & 6,32 & 8,10 & 6,38 \\
\hline Bélgica & 5,92 & 8,35 & 9,06 & 14,22 & 11,31 & 6,68 & 9,16 & 11,16 & 9,02 & 12,30 & 13,36 & 10,33 & 12,95 & 8,29 & 6,96 & 6,56 & 6,81 \\
\hline Canadá & 5,15 & 1,75 & 1,35 & 2,72 & 1,89 & 3,59 & 1,36 & 0,92 & 1,04 & 1,39 & 2,06 & 3,10 & 5,77 & 5,29 & 5,81 & 5,68 & 1,42 \\
\hline EEUU & 3,30 & 3,68 & 1,68 & 0,46 & 0,91 & 8,10 & 7,01 & 6,53 & 6,78 & 5,62 & 7,71 & 7,97 & 5,64 & 7,04 & 6,22 & 3,11 & 5,07 \\
\hline Taiwan & 0,37 & 0,50 & 0,73 & 0,95 & 0,50 & 1,62 & 1,09 & 0,97 & 0,86 & 3,34 & 2,32 & 2,31 & 2,65 & 2,53 & 3,46 & 2,92 & 1,77 \\
\hline $\begin{array}{l}\text { Reino } \\
\text { Unido }\end{array}$ & 4,81 & 4,70 & 5,54 & 3,03 & 4,06 & 3,35 & 3,09 & 2,59 & 6,16 & 1,89 & 1,67 & 1,19 & 1,00 & 3,26 & 0,70 & 2,17 & 1,17 \\
\hline Francia & 3,25 & 4,47 & 4,55 & 4,12 & 3,68 & 2,86 & 2,21 & 1,99 & 3,40 & 4,07 & 5,09 & 4,59 & 3,42 & 3,57 & 3,20 & 2,15 & 1,94 \\
\hline Otros & 50,44 & 52,69 & 49,27 & 47,47 & 48,00 & 44,47 & 43,96 & 46,22 & 37,60 & 32,49 & 28,63 & 28,80 & 33,31 & 23,06 & 19,80 & 21,38 & 13,09 \\
\hline Total & $\begin{array}{l}100,0 \\
0\end{array}$ & $\begin{array}{l}100,0 \\
0\end{array}$ & $\begin{array}{l}100,0 \\
0\end{array}$ & $\begin{array}{l}100,0 \\
0\end{array}$ & $\begin{array}{l}100,0 \\
0\end{array}$ & $\begin{array}{l}100,0 \\
0\end{array}$ & $\begin{array}{l}100,0 \\
0\end{array}$ & $\begin{array}{l}100,0 \\
0\end{array}$ & $\begin{array}{l}100,0 \\
0\end{array}$ & 100,00 & $\begin{array}{l}100,0 \\
0\end{array}$ & $\begin{array}{l}100,0 \\
0\end{array}$ & $\begin{array}{l}100,0 \\
0\end{array}$ & $\begin{array}{l}100,0 \\
0\end{array}$ & 100,00 & $\begin{array}{l}100,0 \\
0\end{array}$ & 100,00 \\
\hline
\end{tabular}

Fuente: Elaboración propia en base a datos de Comtrade

\section{El consumo del litio y la dinámica industrial-tecnológica}

El consumo del litio tiene múltiples modalidades y destinos. En la actualidad el 39\% de lo demandado es para la producción de baterías, el 30\% para cerámicos y vidrios, el 8\% para grasas y lubricantes, el 5\% para metalurgia, otro 5\% para polímeros, un 3\% para tratamientos de aire y el restante $10 \%$ se dirige a fines todavía más heterogéneos. De cara al año 2026 se proyecta que el 70\% del consumo tendrá como destino a las baterías, un $15 \%$ a vidrios y cerámicos, y el 15\% restante a otros destinos (Ministerio de Energía y Minería de la Argentina, 2017).

En este trabajo nos interesa destacar las finalidades ligadas a los bienes que utilizan el litio como insumo central para la producción de tecnología industrial de baterías. Tal como lo indica el Cuadro 3, al comenzar el milenio, Japón era el claro actor dominante del mercado de pilas y baterías en base al sistema Li-ion (explicando el 30\% de lo exportado), seguido por los Estados Unidos (15\%) y luego por un pelotón de países europeos (Alemania, Francia y Bélgica que sumaban el 20\%), donde China ocupaba una posición muy marginal (sólo representaba el 1,46\% del total). Sin embargo, advertimos que China ha crecido rápidamente y pasó a ocupar el primer lugar como exportador mundial, quedando casi a la par con Estados Unidos y Singapur, seguida de un fuerte ascenso de Hong Kong (estos últimos dos, además, funcionan tradicionalmente como reexportadores de la República Popular). Los “perdedores” del proceso para este caso son claros: Japón cayó de manera sostenida como actor central (hoy en día explica menos de la cuarta parte de lo que lo hacía al comenzar el siglo), mientras que las potencias europeas participan prácticamente en la mitad de los valores que tenían antes. Con ello, se 
explica el destino del consumo del recurso primario que analizábamos en la sección previa y queda más que plasmado el avance arrollador de los países del sudeste asiático a la hora tanto de producir como de exportar bienes industriales y tecnológicos de creciente demanda: China, Singapur, Hong Kong, Indonesia y Corea explican más del $50 \%$ de la exportación mundial de estos productos, mientras que los países centrales del capitalismo del siglo XX (Estados Unidos, Alemania, Japón, Francia) se encuentran en retroceso y tienen cada vez menor dinamismo para defender sus posiciones, viéndose entonces opacados por el avance impetuoso de los asiáticos en los mercados que algunas vez dominaron.

\section{Cuadro 3}

Exportación de pilas y baterías de litio en miles de dólares y en porcentaje de participación del mercado según país (2001-2017)

\begin{tabular}{|l|l|l|l|l|l|l|l|l|l|l|l|l|l|l|l|l|l|}
\hline & $\mathbf{2 0 0 1}$ & $\mathbf{2 0 0 2}$ & $\mathbf{2 0 0 3}$ & $\mathbf{2 0 0 4}$ & $\mathbf{2 0 0 5}$ & $\mathbf{2 0 0 6}$ & $\mathbf{2 0 0 7}$ & $\mathbf{2 0 0 8}$ & $\mathbf{2 0 0 9}$ & $\mathbf{2 0 1 0}$ & $\mathbf{2 0 1 1}$ & $\mathbf{2 0 1 2}$ & $\mathbf{2 0 1 3}$ & $\mathbf{2 0 1 4}$ & $\mathbf{2 0 1 5}$ & $\mathbf{2 0 1 6}$ & $\mathbf{2 0 1 7}$ \\
\hline
\end{tabular}

Fuente: Elaboración propia en base a datos de Comtrade

La situación recién descripta es todavía más clara en el pujante mercado de los acumuladores eléctricos en base a litio, un mercado casi ocho veces más grande e importante que el de las pilas y las baterías, no sólo por los valores actuales sino por las promesas de expandirse hacia el futuro a una velocidad muy superior al que pudieran hacerlo aquellas. Los acumuladores permiten un nivel de reserva energética mayor y, hacia adelante, se especula que no solo los hábitos de consumo individuales aumentarán su demanda sino que incluso ciudades enteras requerirán la administración y distribución energética que los acumuladores sean capaces de ofrecer. En los hechos, como datos centrales, se trata de un mercado que ha duplicado su tamaño en apenas cinco años, mientras que el precio de las baterías descendió con igual rapidez, disminuyendo en un 65\% desde 2010 y alcanzando los $\$ 350$ dólares por KWh en el año 2015 (Bloomberg, 2016). De este modo, al seguir los datos provistos por el Cuadro 4, es fácil notar el dominio prácticamente total del sudeste asiático en este terrenodesde 2012.Hay tendencias bastante estables: China, Japón, Corea, Hong Kong y Singapur explican tres cuartas partes del total-siendo entonces un cartel casi oligopólicoy dejan en una posición rezagada a Estados Unidos y a Alemania (sumados, ambos países explican apenas el 10\%).

Cuadro 4: Exportación acumuladores de litio en miles de dólares y en porcentaje de participación del mercado según país (2012-2017)

\begin{tabular}{|c|c|c|c|c|c|c|}
\hline & 2012 & 2013 & 2014 & 2015 & 2016 & 2017 \\
\hline \multicolumn{7}{|c|}{ En millones de dólares } \\
\hline Mundo & 11.473 & 13.111 & 14.242 & 15.399 & 17.704 & 20.264 \\
\hline \multicolumn{7}{|c|}{ Participación porcentual en el mercado } \\
\hline China & 38,91 & 35,90 & 38,44 & 42,22 & 38,29 & 31,05 \\
\hline Japón & 19,99 & 15,66 & 14,27 & 13,20 & 14,77 & 12,70 \\
\hline Corea & 18,00 & 17,28 & 15,92 & 13,18 & 13,15 & 17,36 \\
\hline Hong Kong & 9,78 & 11,29 & 9,79 & 9,28 & 8,54 & 10,73 \\
\hline Estados Unidos & 2,11 & 5,04 & 5,29 & 5,18 & 6,29 & 6,36 \\
\hline Alemania & 2,41 & 3,49 & 3,82 & 3,19 & 3,32 & 4,73 \\
\hline Singapur & 1,52 & 1,73 & 2,15 & 2,36 & 2,15 & 2,80 \\
\hline Otros & 7 & 10 & 10 & 11 & 13 & 14 \\
\hline
\end{tabular}

Fuente: Elaboración propia en base a datos de Comtrade 
Si analizamos cuáles son los países que consumen este tipo de bienes industriales, aquí también notaremos la ratificación de las tendencias descriptas anteriormente, aunque explicada de manera diferente. Para el caso de la importación de pilas y baterías de litio, por un lado se percibe un claro aumento de lo demandado por las potencias asiáticas: Hong Kong, Singapur, China, Malasia y Corea pasaron de explicar el 18\% del consumo mundial en 2001, a explicar el 33\% en la actualidad (lo que equivale a un crecimiento del 84\%). Ello da cuenta no sólo de su avance económico sino también de la mejora en el estándar de consumo de la población como consecuencia del mismo crecimiento económico. Así, la imagen de la "Fábrica Asia" o bien de "Asia laboratorio" hay que acompañarla con otra que evidencia un mercado de consumo igual de amplio. Por otro lado, vemos en el Cuadro 5 que las potencias atlánticas del siglo XX explicaban tanto en 2001 como en la actualidad el 33\% de lo demandado, sin existir cambios y sólo manteniéndose en el mismo ritmo en que se movió el mercado. Sin embargo, al analizar la importación de los acumuladores de litio, un rubro mucho más importante expuesto en el Cuadro 5, notamos que la fisonomía se cristaliza de manera todavía más clara. Las potencias centrales del siglo XX duplicaron su consumo entre 2012 y 2017 en un mercado que creció en un 70\% en apenas cinco años, pasando dichas potencias de explicar el $22 \%$ a casi el $44 \%$ de lo importado, es decir que su consumo creció a una velocidad fenomenal. Este punto es importante porque -como ya mencionamos- delata que el capitalismo occidental exporta cada vez menos bienes de alto valor agregado como son los acumuladores, pero en cambio se está volviendo a toda velocidad el principal comprador y consumidor de lo que fabrica el oligopolio exportador asiático, todo un signo de nuestros tiempos y un representativo panorama de cómo cambiaron las relaciones económicas en términos de bloques geopolíticos: ya no es más occidente la vanguardia industrial en las nuevas tecnologías, sino que progresivamente deja de exportar para pasar a consumir los bienes que el sudeste asiático produce.

A su vez, como contracara directa de este proceso, se observa que China, a pesar de crecer como exportador mundial de acumuladores, importa este tipo de bienes cada vez menos, pudiendo no sólo abastecer crecientemente a su inmenso mercado interno sino también producir lo suficiente como para ser el principal vendedor internacional.

\section{Cuadro 5 \\ Importación acumuladores de litio en miles de dólares y en porcentaje de participación del mercado según país (2012-2017)}

\begin{tabular}{|c|c|c|c|c|c|c|}
\hline & \begin{tabular}{|l|}
2012 \\
\end{tabular} & 2013 & \begin{tabular}{|l|}
2014 \\
\end{tabular} & 2015 & 2016 & 2017 \\
\hline \multicolumn{7}{|c|}{ En millones de dólares } \\
\hline Mundo & 10.174 & 11.447 & 12.971 & 13.805 & 15.406 & 17.330 \\
\hline \multicolumn{7}{|c|}{ Participación porcentual en el mercado } \\
\hline China & 38,98 & 28,98 & 26,40 & 23,89 & 19,88 & 14,71 \\
\hline Estados Unidos & 12,84 & 14,92 & 13,34 & 12,51 & 12,98 & 14,85 \\
\hline Hong Kong & 12,38 & 13,59 & 11,57 & 11,80 & 11,34 & 11,99 \\
\hline Alemania & 5,56 & 5,91 & 7,95 & 10,00 & 10,90 & 12,93 \\
\hline VietNam & 1,95 & 1,59 & 5,19 & 4,84 & 5,27 & 0,00 \\
\hline Japón & 5,13 & 5,72 & 4,14 & 4,59 & 4,87 & 4,66 \\
\hline Países Bajos & 1,23 & 1,52 & 2,85 & 3,70 & 3,67 & 5,26 \\
\hline Francia & 2,03 & 3,33 & 3,21 & 2,65 & 2,69 & 3,40 \\
\hline Corea & 4,56 & 4,47 & 3,56 & 2,92 & 2,56 & 3,87 \\
\hline México & 0,35 & 1,50 & 2,35 & 2,66 & 2,34 & 2,14 \\
\hline Reino Unido & 0,81 & 0,98 & 1,23 & 1,75 & 2,33 & 2,39 \\
\hline India & 0,00 & 1,46 & 0,98 & 1,47 & 1,98 & 2,70 \\
\hline Otros & 14,18 & 16,03 & 17,22 & 17,23 & 19,20 & 21,10 \\
\hline
\end{tabular}

Fuente: Elaboración propia en base a datos de Comtrade

La vigorosa pujanza del capitalismo asiático con vistas al litio empieza a ser clara: es la zona principal de consumo del recurso pero también la que se ocupa de reelaborarlo en bienes industriales y tecnológicamente de punta, desplazando cada vez más a las economías capitalistas que dominaron el siglo XX. Dichas dinámicas proyectan volverse todavía más apabullantes de cara al futuro, puesto que los desarrollos en investigación e innovación de conocimiento tecnológico son también dominantes aquí, tal como analizaremos en la próxima sección. 


\section{Investigación e innovación ligadas al litio a escala global}

El conocimiento científico es uno de los pilares esenciales para la innovación. Dar cuenta de los países que concentran la producción científica nos permitirá completar el panorama sobre cómo se estructuran los centros de producción de tecnología en la cadena de agregado de valor del litio a nivel global.

Una manera de abordar el estudio sobre cómo se distribuye la producción de conocimiento a nivel global es mediante el análisis de indicadores bibliométricos. En particular, los indicadores de producción miden la cantidad de publicaciones originadas por un autor, país o institución durante un determinado período. La ventaja de dichos indicadores es que pueden ser aplicados a un gran volumen de datos, posibilitando la obtención de información representativa de las tendencias mundiales. Aunque los indicadores de producción presentan la limitación de incluir solo aquellos documentos publicados en revistas indexadas -esto es, revistas que están contenidas en bases de datos digitales- consideramos que es pertinente relacionarlos con los datos de importación y exportación del recurso primario y de los bienes tecnológicos que analizamos en las secciones previas.

En el marco de este trabajo, presentaremos algunos indicadores de producción obtenidos de la base de datos Scopus de la editorial Elsevier ${ }^{7}$.En líneas generales podemos ver que entre los años 1900 y 2017 los documentos conteniendo la palabra "litio" en su título, palabras clave o resumen, crecieron de forma constante, aunque no de manera sostenida sino con tres subperíodos muy claros (Gráfico 5). El lapso que va de 1960 a 1990 presenta una tasa de crecimiento de 95 documentos por año. A partir de 1970, la proporción de la producción científica publicada en revistas de editoriales privadas aumentó de manera constante y más aún desde el advenimiento de la era digital. Desde entonces, las revistas indexadas y con factor de impacto alto se consideran "de prestigio" en la comunidad científica, y los indicadores de producción se transformaron en la forma hegemónica de evaluar tanto a investigadores como a las instituciones a las cuales pertenecen. Ello explica, en parte, el incremento en la tasa de documentos anuales en el segundo subperíodo (1990-2010) que ascendió a 220. No obstante, es necesario mencionar una particularidad de las investigaciones en torno al litio. A comienzos de la década de 1990 se incorporó en el mercado la primera batería de ion-litio por parte de la marca SONY ${ }^{\circledR}$, lo cual desencadenó una explosión de la producción de este tipo de baterías y que buena parte de las investigaciones se orientaran a mejorar -aún más- su desempeño, capacidad y estabilidad. El tercer subperiodo del Gráfico 5, que corresponde a los últimos siete años (2010-217), presenta una tasa de crecimiento que trepó a 1229, en línea con el boom de las energías renovables y el papel del litio en los sistemas de almacenamiento de energía.

\section{Gráfico 5}

Número de documentos científicos que contienen la palabra "litio" a nivel mundial

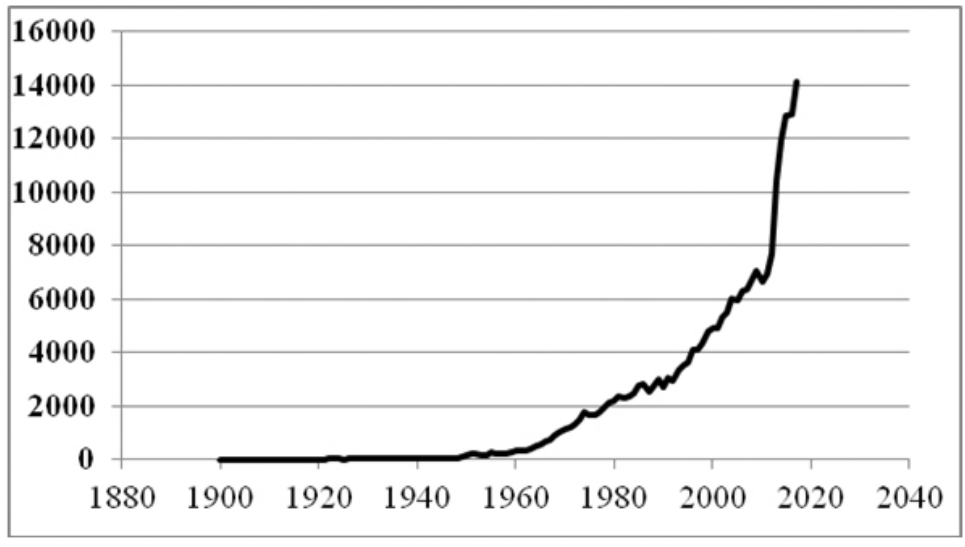

Fuente: Elaboración propia en base a datos de Scopus 
Estas tendencias se expresan también en la evolución de los documentos científicos que incluyen la expresión "baterías de litio" yque hemos plasmado en el Gráfico 6. Allí confirmamos que la explosión de producción científica sobre litio a partir de 1990 y su crecimiento exponencial desde el año 2010 (Gráfico 5) se explica con el incremento en las investigaciones direccionadas a los sistemas de almacenamiento de energía. En términos generales, el aumento sostenido de las publicaciones científicas sobre litio, y particularmente sobre baterías de litio, en línea con el crecimiento en la exportación de sistemas de almacenamiento energéticos basados en este metal, es un indicador de la consolidación de esta tecnología a nivel mundial.

\section{Gráfico 6}

\section{Número de documentos científicos conteniendo la palabra "baterías de litio" a nivel mundial ${ }^{9}$}

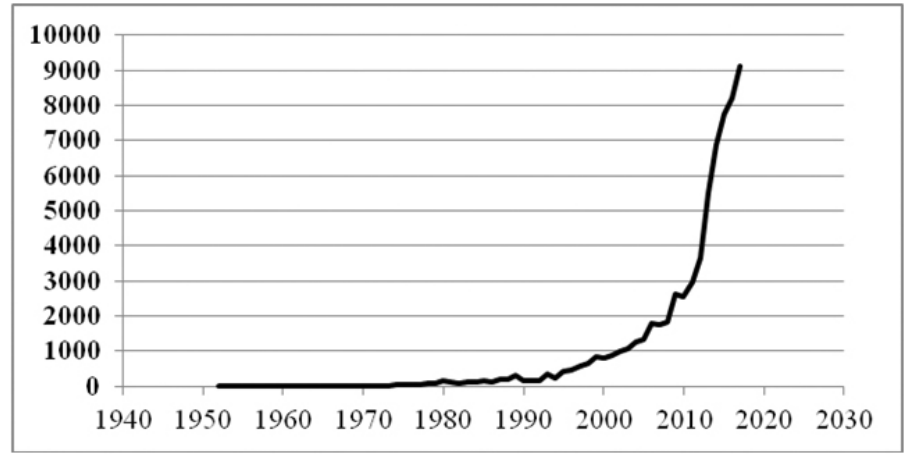

Fuente: Elaboración propia en base a datos de Scopus

Si consideramos la procedencia de los autores de los documentos, vemos que los países que generan los mayores índices de producción son indefectiblemente las naciones centrales (Gráficos 7 y 8). Al analizar cómo se distribuye la producción de documentos científicos sobre "litio" a nivel mundial (esto es, conocimiento teórico y aplicado, asociado al metal y su uso tanto en acumuladores de energía, fármacos, grasas lubricantes, etc.), vemos que Estados Unidos lleva la delantera con el 21\% del total, seguido por China (14\%) y Japón (8\%) y luego los países europeos: Alemania, Reino Unido y Francia que, juntos, explican el 15\% del total de documentos (Gráfico 7).

\section{Gráfico 7}

\section{Distribución porcentual de los documentos científicos conteniendo la palabra "litio" por país} (1900-2017)

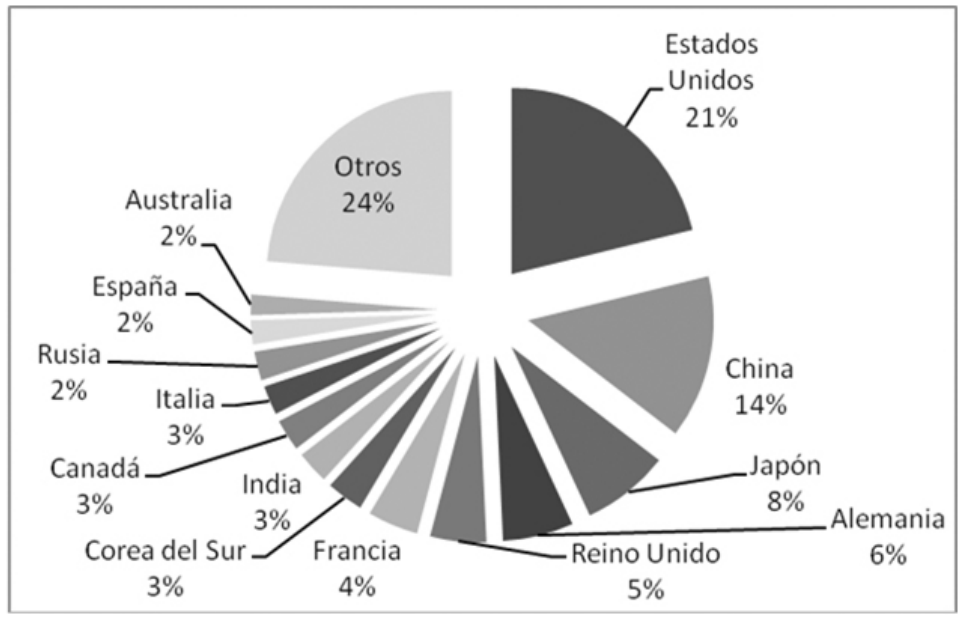

Fuente: Elaboración propia en base a datos de Scopus 
Si Estados Unidos explicaba la cuarta parte de las investigaciones publicadas sobre litio, cuando de baterías de litio se trata es China quien toma la delantera y explica el 31\% de los documentos producidos, seguido por Estados Unidos (que representa el 16\%), Japón (que mantiene el tercer lugar con el 8\%). Corea del Sur ocupa el cuarto lugar con un 7\%, desplazando a los países europeos (Alemania, Francia y Reino Unido) que juntos concentran un 10\% del total (Gráfico 8).

También advertimos en esta esfera de conocimiento el ascenso de India como productor de investigaciones, que supera en términos porcentuales al Reino Unido. Una vez más asistimos a una notoria mutación del eje de los centros de producción de conocimiento. Estamos frente a un fenómeno similar al analizado respecto a la importación del recurso y exportación de bienes industriales en base al litio: China junto al resto de los países asiáticos representan el $49 \%$ del total de trabajos reportados dejando en lugares cada vez menos significativos y decrecientes a las viejas potencias mundiales europeas y a Estados Unidos. La esfera de la investigación e innovación es vital puesto que es una de las más importantes para consolidar en el tiempo las dinámicas y transformaciones reseñadas en los apartados anteriores.

\section{Gráfico 8 \\ Distribución porcentual de los documentos científicos conteniendo las palabras “baterías de litio" por país (1952-2017)}

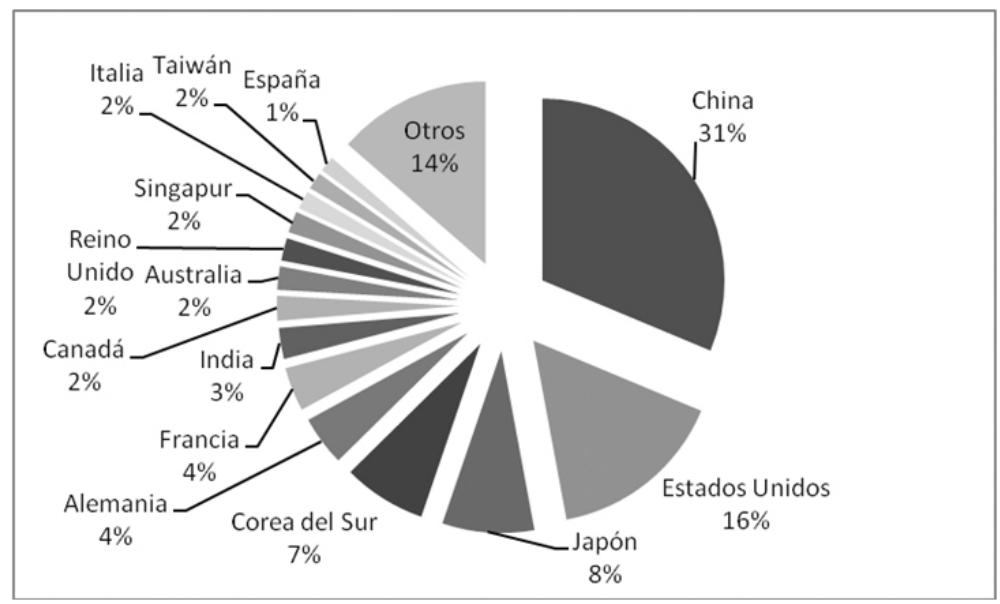

Fuente: Elaboración propia en base a datos de Scopus

Esto se puede relacionar con el rol preponderante que están teniendo los países asiáticos en el desarrollo de conocimientos y tecnologías asociadas a las energías limpias, en busca de pasar del “made in” al "createdby". Al indagar más notamos que Estados Unidos, a diferencia de China, presenta documentos desde comienzo del siglo XX y a partir de 1940 una tasa de crecimiento del número de publicaciones que se mantuvo constante hasta 2010, donde incrementa a razón de 152 trabajos por año ${ }^{10}$ (Gráfico 9). 


\section{Gráfico 9}

\section{Número de documentos científicos conteniendo la palabra “litio” en Estados Unidos}

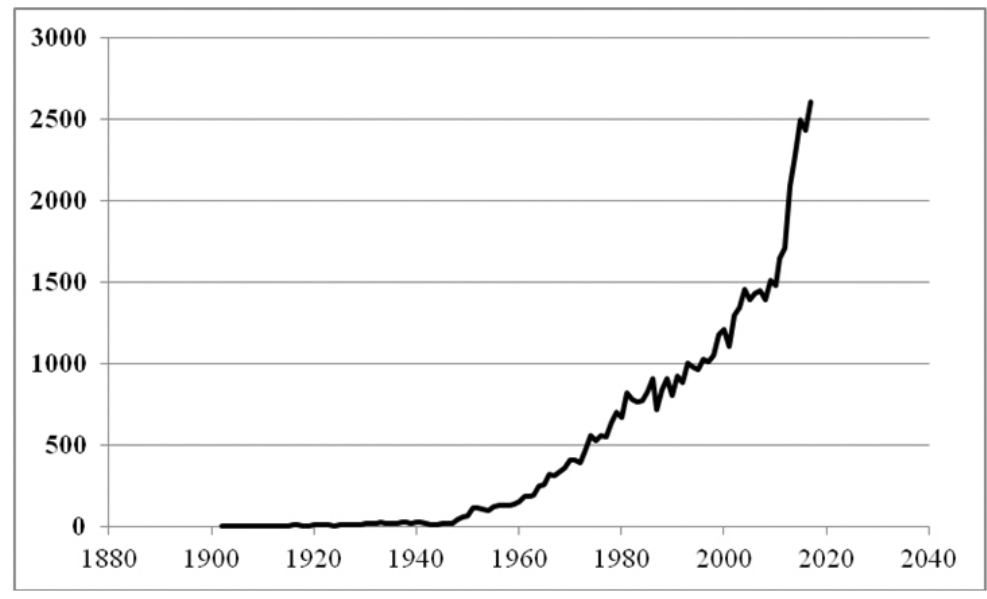

Fuente: Elaboración propia en base a datos de Scopus

Si consideramos especialmente el caso de China, vemos que presenta la primera publicación de forma más tardía que Estados Unidos pero el incremento en las publicaciones desde 2010 es de $573^{10}$, un 370\% más que Estados Unidos, es decir, crece a una tasa significativamente mayor (Gráfico 10). En este sentido, no sólo el eje del consumo del recurso o la exportación de tecnología se corrió hacia el sudeste asiático, este viraje también se verifica en los indicadores de producción científica en relación al metal.

De esta manera, las perspectivas de que China pueda continuar desplazando e incluso dominar con comodidad los productos industriales y las tecnologías de punta no debe descartarse, ya que como vemos, en función de la investigación e innovación ligada al litio -así como también en la producción tecnológica industrial en general- existe un claro desplazamiento de los ejes económicos en el mundo. Esto puede relacionarse con el esfuerzo que China está haciendo en pos del desarrollo de la industria energética y de posicionarse a nivel global a la vanguardia de un nuevo paradigma energético, hecho que ilustramos en el siguiente apartado.

\section{Gráfico 10}

Número de documentos científicos conteniendo la palabra "baterías de litio" en China

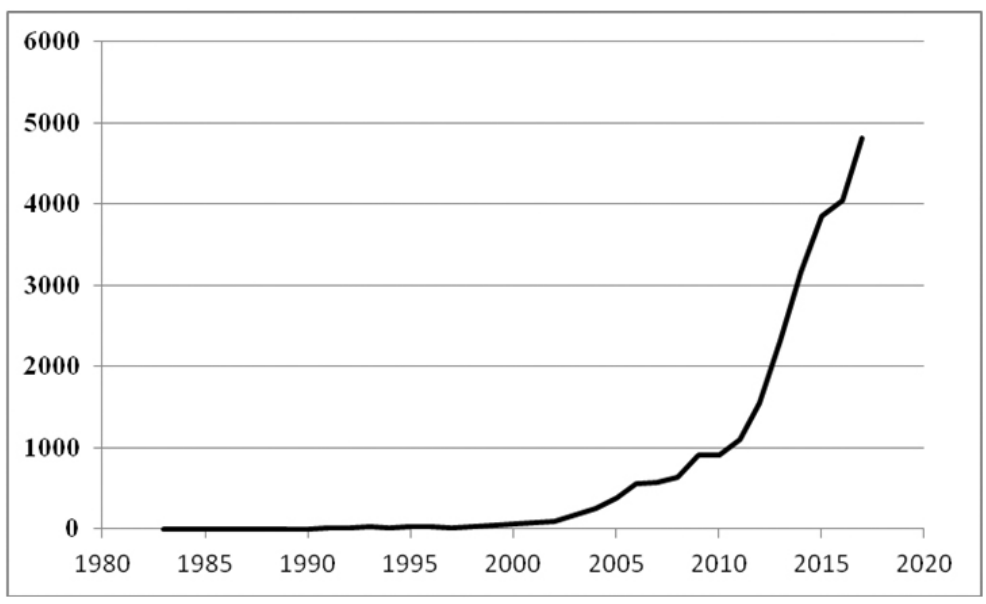

Fuente: Elaboración propia en base a datos de Scopus 


\section{China, nueva energía y mercado automotriz}

Hasta hace unos años, China no cumplía el Protocolo de Kyoto, desestimaba las presiones de Estados Unidos y Europa para que asumiera sus responsabilidades respecto del cambio climático y afirmaba que haría uso de sus prerrogativas de un país en desarrollo, postura que esgrimió aún en la Cumbre de Copenhague de 2009. Sin embargo, tal como afirma Ríos (2017), China ha protagonizado "una larga marcha hacia la conciencia ambiental” (Ríos, 2017, p. 78): ya en el 2012 el Congreso del Partido Comunista Chino (PCC) afirmó la necesidad de crear una "civilización ecológica" (Ibid). Es otra de las maneras de legitimarse como potencia global, ya no desconoce su responsabilidad en el cambio climático pero como contrapartida se le debe reconocer su real estatura en la comunidad internacional. A diferencia de lo que realiza en este momento el presidente norteamericano Donald Trump-quien promete extraer todo el combustible no-convencional estadounidense a la par que niega el cambio climático-, el PCC advirtió la potencialidad de redirigir la problemática energética, lo cual no significa que no sea (y siga siendo) por un buen tiempo una locomotora que avanza quemando carbón y aspirando petróleo (Fornillo, 2016).

Las estrategias del país para combatir esta situación son múltiples: modificar su entorno energético; externalizar los costos ambientales de la cadena productiva hacia los países periféricos del "sur global”; relocalizar las industrias más intensivas (mano de obra, energía y ambiente); y, generar una industria verde. Por esta línea, se trata de ampliar su rango de generación renovable, también a causa del padecimiento en sus ciudades por la contaminación atmosférica. De acuerdo con la Agencia Internacional de Energía, entre los años 2015 y 2021, China instalará el 36\% de toda la capacidad de generación de energía hidroeléctrica mundial, el 40\% de toda la energía eólica y el 36\% de la energía solar global (AIE, 2016). Asimismo, se trata de una evidente oportunidad de desarrollo, ya que la potencia asiática desplegó un ambicioso plan de renovación con el objetivo de lograr una mayor soberanía energética, aminorar la dependencia de los combustibles fósiles, proteger el medioambiente, acceder a nueva tecnología y participar del mercado próximo: proyecta duplicar la exportación de "tecnología e industria verde” para el 2030 alcanzando los 400 mil millones de dólares (Fornillo, 2016). En este sentido, es probable que se amplíe el liderazgo global de China en las industrias del futuro dado el dominio asiático en términos de tecnología, inversión, fabricación y empleo en el nuevo paradigma energético, dejando a EEUU atrás (Buckley y Nicholas, 2017).

Un indicador particularmente interesante lo constituye la industria automotriz. China espera en el año 2025 tornarse autosuficiente y dentro de ella ha decidido que entrará al mercado automotriz por vía de lo nuevo: los autos eléctricos. Ciertamente, no es la californiana Tesla la que mayores ventas de autos eléctricos realizó en el año 2017 sino BYD, asentada en Shenzhen: vendió 70.000 autos eléctricos en los primeros tres trimestres de 2017. Según la Agencia Internacional de Energía, el año 2016 ha traído consigo un nuevo record con 750 mil nuevos autos eléctricos en todo el mundo. Fue un año en el que "China fue, con mucho, el mayor mercado de automóviles eléctricos, representando más del $40 \%$ de los autos eléctricos vendidos en el mundo y más del doble de la cantidad vendida en los Estados Unidos” (AIE, 2017, 5), siendo además el año en que superó en stock de automóviles eléctricos a EEUU. Con todo, China aún es un mercado de futuro en gestación, existen "apenas" dos millones de vehículos eléctricos que representan tan solo el $0,3 \%$ del mercado global, pero se expande sin freno: el mercado Chino creció entre 2015 y 2016 el 69\%, el 7\% lo hizo Europa, y EEUU un 37\%. La Agencia Internacional de Energía afirma que el stock de vehículos eléctricos oscilará entre 9 millones y 20 millones para 2020, y entre 40 millones y 70 millones para 2025 (AIE, 2017). Según Bloomberg New Energy Finance, para 2040 habrá 530 millones de automóviles eléctricos en todo el mundo, lo que representará un tercio de todos los automóviles, es decir, una tecnología consolidada fundamentalmente debido al progresivo descenso del precio de las baterías de litio y paralelo al progresivo aumento del precio de los combustibles fósiles (Bloomberg, 2016).

Para el caso de China no se trata de una tecnología importada, sino que la misma fabricación de vehículos corre por cuenta de constructores locales: las firmas chinas produjeron el $43 \%$ de los 750.000 vehículos eléctricos lanzados en todo el mundo en 2016 (Hertzkeet al., 2017). Se espera que los fabricantes de automóviles chinos produzcan más de 4,5 millones de vehículos eléctricos al año en 2020, en comparación con el millón que proyecta la californiana Tesla. China está, en efecto, en el centro de la reinvención de la industria automotriz mundial, fenómeno impensable hace unos años al contemplar la clásica bicicleta negra que corría interminable por las calles de Pekín. 


\section{El mercado global del litio de Norte a Sur}

En el último tiempo, la tecnología del litio ha tendido a consolidarse como reservorio de electricidad si se la compara con la relatividad de su peso apenas cinco años (Fornillo, 2015). Hoy en día el mercado es cada vez más profundo, grandes corporaciones realizan sus planes de negocios a futuro en base a la tecnología del litio, aumentan las exportaciones del mineral y la investigación sobre la cuestión litífera crece sin freno, de modo que se han acrecentado las chances de que se convierta en un vector privilegiado del nuevo paradigma energético.

Ahora bien, hemos tratado de evidenciar una mutación del eje geopolítico global sobre el cual se despliegan las nuevas tecnologías verdes, lo cual a su vez impacta sobre el modo en cómo debe considerarse a la energía del litio en particular, ya que no es posible pensarla sin este marco global. En él, se torna evidente que el alcance de la multipolarización ha sido tan vasto que no estamos lejos de la concreción sinocentrista según la cual el "reino del medio" está en el centro de todo lo que brilla bajo el cielo. Más bien, hemos comprobado que esa realidad tiende a emplazarse lenta pero persistentemente. Ello es así debido a que el eje asiático, que pivotea principalmente en torno al "gigante asiático", por un lado se encuentra articulando un circuito económico cerrado de producción y consumo cada vez más amplio, capaz de volverse autosuficiente y de situarse en la frontera tecnológica, desplegando su propio entorno de innovación. Hemos dado cuenta de un circuito económico completo autocentrado: se repasó el consumo del litio, su cadena de valor, el mercado de las baterías, la investigación e innovación de acumuladores, y en el terreno de mayor complejidad y agregación de valor como es la industria automotriz, vimos la consolidación del dominio de la nueva Asia.

Es también importante subrayar aquí que la dirección central que hemos demostrado no significa la definitiva declinación de las potencias tradicionales, los países atlánticos despliegan sus estrategias para torcer las tendencias dominantes en un cuadro de situación que no está cerrado, aclaración necesaria para ser justos con una dinámica de por sí compleja. Por el otro, esa iniciativa se realiza entremedio del nuevo paradigma energético, que deberá acarrear una nueva ecología productiva para el conjunto del orden global, ya que es preciso adoptar una bifurcación que permita esquivar el derrotero sinuoso de nuestra sociedad fósil. En este marco, la energía del litio se sitúa en un lugar especialmente interesante, puesto que forma parte del mismo ímpetu de desarrollo pero participa, a su vez, de los atisbos de estrategias de posdesarrollo que puedan alumbrar nuestras sociedades; esto es, políticas tendientes a descentralizar, desmercantilizar y desmaterializar nuestros patrones de producción y consumo, aunque esta posibilidad no se encuentre más que en ciernes (Unceta, 2014).

Siendo este el paisaje general, la constatación sobre la preeminencia China por sobre las potencias atlánticas no posee un sentido mayor, se trata simplemente de subrayar un cierto corrimiento del eje de acumulación global que no necesariamente es definitivo, pero sin el cual tampoco es posible comprender dinámicas estructurantes que impactan de manera directa sobre el "sur global". En efecto,existe un corrimiento de las áreas más dinámicas de desarrollo de las fuerzas productivas pero, con igual claridad, se reproduce un lugar subsidiario del "sur global", cuya presencia se reduce a la de un espectador pasivo de dinámicas más complejas que se tejen en el centro, aunque aporte el componente esencial que las posibilita: el litio. El corrimiento del eje no cambió el patrón de inserción internacional de la región, donde la relación de dominio ahora parece asentarse por el poder tecnológico más que por el industrial o financiero, como lo era antes. De aquí que los desafíos para los exportadores del recurso primario impliquen trazar una estrategia alternativa y no ser sólo los vendedores de materia primera; es decir, redefinir su inserción en los mercados mundiales, escalando en la cadena de valor tanto del litio como a nivel general.

En este sentido, la transformación en los ejes de acumulación en el "norte global” se está produciendo a una velocidad cada vez mayor, por lo que el "sur global” debería también intentar cambios. Eso es especialmente cierto si se echa una mirada a las estrategias que están desplegando los diferentes actores en el terreno de la reconfiguración global. Porque mientras el avance de Asia -especialmente el de China- sigue modificando y poniendo a la defensiva a las añejas potencias (Slipak, 2016; 2018), éstas no se entregan pasivamente a la resignación. Por ejemplo, los países europeos más que competir entre ellos por dominar los mercados de manera individual, parecen buscar lógicas cooperativas de funcionamiento en vistas a las nuevas tecnologías. Una 
táctica que, en el terreno de las baterías de litio, parece replicar lo ya ensayado en otros asuntos como los trenes de alta velocidad o el proyecto insignia europeo Airbus. Tal es así, que a principios del año 2019 los ministros de economía de Alemania y Francia anunciaron una estrategia productiva común para la Unión Europea, con el objetivo de crear "nuevos campeones" industriales, y el inicio de este horizonte continental consiste en consolidar la fabricación de baterías eléctricas. La situación de Estados Unidos, especialmente una vez llegado Trump a la presidencia, parece más bien insistir con las viejas recetas para que el país no quede rezagado: enfrenta los desafíos con estímulos al desarrollo de algunas empresas tecnológicas vía subsidios y gasto estatal, sube sus aranceles y se embarca en el proteccionismo en pos de una guerra comercial redentora, todo ello sin renunciar del todo al militarismo para defender su zonas de influencias o retrasar el poderío asiático. Para el caso de los países latinoamericanos, las actitudes y reacciones hasta ahora han sido débiles o incluso inexistentes, entregándose en la mayoría de los casos a la resignación de tener una posición subordinada. En este contexto global, si la región no procura replantear sus estrategias de manera más enérgica, continuará estancada en una posición doblegada sin otro futuro más que adentrarse a una neodependencia.

\title{
Notas
}

\begin{abstract}
${ }^{1}$ Dadas las heterogeneidades con las que se transa el producto entre países se suelen hacer estimaciones de "homogeneización” en base al denominado "Equivalente de Carbonato de Litio" (o LCE, según sus siglas en inglés).

${ }^{2}$ El principal país comprador del litio australiano es China, quien por los bajos niveles de oxidación del recurso que compra de allí (cercanas al 6\%) luego lo procesa hasta llegar al carbonato e hidróxido de litio. Como señalamos, quitar las exportaciones de litio australianas modifica sensiblemente las series mundiales convencionales, puesto que si se considera la medida estándar de Equivalente de Carbonato de Litio dicho país sería el primer productor mundial con el $40 \%$ del mercado. Pero dado que no procesa el recurso -algo a considerar en este escrito- su rol como exportador se reduce a un lugar casi nulo. Existen algunos otros derivados como cloruros y sulfatos de litio, los cuales representan mercados muy marginales para el producto en su comercialización mundial, por lo que tampoco se los analizará.
\end{abstract}

${ }^{3}$ Un debate sobre lo que se consideran recursos, reservas identificadas y cómo medirlas, se puede encontrar en: Riva Palacio (2012), COCHILCO (2009) y Lagos (2017).

${ }^{4}$ En tanto aclaración metodológica, es preciso notar que las cantidades comercializadas de carbonato, óxido e hidróxido de litio plasmadas en el Gráfico 3 representan el valor promedio de lo vendido y comprado en el mundo. Hemos optado por esta forma dado que las importaciones se miden en CIF y las exportaciones en FOB, por lo cual los precios que reciben los productores y que pagan los consumidores nunca es el mismo, existiendo una brecha de precios y valores explicada por los costos de transporte, seguros, impuestos y demás ítems de comercialización.

${ }^{5}$ Debe señalarse que no existe un mercado único de los productos de litio analizados hasta ahora ni tampoco éstos se comercializan "a granel”. Por lo cual, no existe un precio de referencia único sino que incluso pueden existir variaciones muy grandes entre los precios recibidos y pagados por los distintos países, según el año. Por ello, ante la carencia de un valor único hemos logrado construir un indicador que nos permita aproximarnos a la evolución de lo comerciado. Esto se hizo de la siguiente forma: se tomaron los valores exportados e importados respectivamente y se los desflacionaron por las cantidades informadas por los países, obteniendo un precio de referencia exportador e importador anual que luego se promedió entre sí para obtener un indicador todavía más sólido. En el caso del carbonato del litio, entre 2003-2009 sólo se tomó el precio importador por existir muchas discrepancias en las cantidades de exportación informadas por Chile, lo que llevaba a distorsionar severamente la serie.

${ }^{6}$ Un análisis de los costos de producción del recurso según los salares de los diferentes países puede encontrarse en Zícari (2015a).

${ }^{7}$ Scopus es la base de datos más grande del mundo, concentrando 22.878 revistas científicas de las 150.000 que, se estima, circulan en todo el globo. Teniendo en cuenta que apenas el 20\% de las revistas están indexadas, el universo Scopus representaría el 75\% del total de publicaciones que pueden ser incluidas en indicadores bibliométricos. Para un debate sobre la utilización de los indicadores bibliométricos en la evaluación de la producción científica, véase: Cátedra CPS (2015).

${ }^{8}$ La búsqueda en Scopus de documentos (artículos -papers y reviews-, artículos cortos -notes- y capítulos de libros -bookchapters-) conteniendo la palabra “lithium" en su título, resumen y/o palabras clave arroja 228.863 resultados en el período 1900-2017.

${ }^{9}$ La búsqueda en Scopus de documentos (artículos -papers y reviews-, artículos cortos -notes- y capítulos de libros -bookchapters-) conteniendo las palabras "lithiumbatteries” en su título, resumen y/o palabras clave, restringido a las áreas de conocimiento: química, ciencia de los materiales, ingeniería, ingeniería química, energía y física arroja 66964 resultados en el período 1952-2017.

${ }^{10}$ Dato obtenido del análisis matemático de los datos, mediante regresión lineal -método de cuadrados mínimos-. 


\section{Bibliografía}

AIE. (2016).World Energy Outlook. Recuperado de: www.iea.org

AIE. (2017).Global EV Outlook. Recuperado de: www.iea.org

Bloomberg. (2016). Vehículos eléctricos representarán el 35\% de las ventas globales de automóviles en 2035. Recuperado de: www.bloomberg.com

Buckley, T. y Nicholas, S. (2017).China Renewableenergyexpansion. Instituteforenergyeconomics y financial análisis.Recuperado de: www.ieefa.org

Cátedra CPS. (2015). Publicaciones científicas: ¿comunicación o negocio editorial? Recuperado de: www.blogs.unlp.edu.ar

COCHILCO,Dirección de Estudios y políticas públicas. (2009).Antecedentes para una política pública en minerales estratégicos: Litio, Santiago de Chile, Chile.

Fornillo, B. (coord.). (2015).Geopolítica del litio. Industria, ciencia y energía en la Argentina. Buenos Aires, Argentina:El Colectivo-CLACSO.

Fornillo, B. (2016).Sudamérica futuro. China global, transición energética y posdesarrollo.Buenos Aires, Argentina: El Colectivo-CLACSO.

Hertzke, P., Nicolai, M. y Schenk, S. (2017).Dynamics in the global electric-vehicle market. McKinsey Center forFutureMobility. Recuperado de: www.mckinsey.com

Lagos, G. (2017).El desarrollo de litio en Chile: 1984-2017.Santiago de Chile,Chile: Editec.

Ministerio de Energía y Minería de Argentina. (2017).El litio argentino. Situación actual y perspectivas. Recuperado de: www.editorialrn.com.ar

Rios, X. (2017). China: el gran salto ambiental.,(81),77-82.

Riva Palacio, L. (2012). Del triángulo del litio y el desarrollo sustentable. Una crítica del debate sobre la explotación en Sudamérica en el marco del desarrollo capitalista. Recuperado de: http://www.geopolitica.ws.

Slipak, A. (Noviembre de 2016). Políticas de la República Popular de China ante el cambio climático, su seguridad energética e implicancias para América Latina.En J.Neffa (Presidencia), II Congreso de Economía Política Internacional. Congreso realizado en la Universidad Nacional de Moreno (UNM), Moreno, Argentina.

Slipak, A. (2018). Las relaciones entre China y Alemania en el tablero de la Economía Política Internacional. Una mirada desde América Latina, RealidadEconómica (en prensa).

Ströbele-Gregor, J. (2015). Desigualdades estructurales en el aprovechamiento de un recurso estratégico. La economía global del litio y el caso de Bolivia.WorkingPaper Series, (79).

Unceta, K. (2014).Poscrecimiento, desmercantilización y 'buen vivir'. Nueva Sociedad,(252), 136-152.

Zícari, J. (2015a). El mercado del litio desde una perspectiva global: de la Argentina al mundo. Actores, lógicas y dinámicas.En Fornillo, B. (Coord.),Geopolítica del litio. Industria, ciencia y energía en Argentina (pp. 1956), Buenos Aires, Argentina:El Colectivo-CLACSO.

Zícari, J. (2015b). La producción minera de litio en América Latina y el ascenso económico de China y de Asia Oriental, Revista Economía, (67), 93-112. 


\section{Estadísticas}

Comtrade (www.comtrade.org)

Scopus (www.scopus.com) 